\begin{tabular}{|l|l|l||}
\hline \multicolumn{2}{|c|}{ PublisherInfo } \\
\hline \hline PublisherName & $:$ & BioMed Central \\
\hline \hline PublisherLocation & $:$ & London \\
\hline \hline PublisherImprintName & $:$ & BioMed Central \\
\hline \hline
\end{tabular}

\title{
Use of adenosine in coronary artery bypass surgery
}

\begin{tabular}{|l|l|l||}
\hline \multicolumn{2}{|c||}{ ArticleInfo } \\
\hline \hline ArticleID & $:$ & 4110 \\
\hline \hline ArticleDOI & $:$ & $10.1186 /$ ccf-1999-331 \\
\hline \hline ArticleCitationID & $:$ & 331 \\
\hline \hline ArticleSequenceNumber & $:$ & 47 \\
\hline \hline ArticleCategory & $:$ & Paper Report \\
\hline ArticleFirstPage & $:$ & 1 \\
\hline \hline ArticleLastPage & $:$ & 3 \\
\hline \hline & & RegistrationDate : 1999-5-18 \\
ArticleHistory & $:$ & OnlineDate \\
\hline \hline ArticleCopyright & $:$ & Current Science Ltd1999-5-18 \\
\hline \hline ArticleGrants & $:$ & \\
\hline \hline ArticleContext & $:$ & 130541111 \\
\hline \hline
\end{tabular}




\section{Keywords}

Adenosine, cardioplegia, coronary artey bypass surgery, outcome

\section{Comments}

An interesting study trying to define the benefit of adenosine in CABG surgery. The authors provide a lucid discussion of the rationale and possible mechanism of action of this purine, building on previous work. A number of interesting comments were made in the paper. For instance, measuring total dopamine use does not distinguish between inotrope dependence and use. This may have contributed to the lack of difference in this parameter between groups. Hence the logic of measuring high dose dopamine requirements. Additionally, it is postulated that benefits from adenosine may be more marked if used in higher risk patient sub-groups (overall mortality was 3.6\% in the study). The discussion panel at the end of the paper provides additional commentary.

\section{Introduction}

Coronary artery bypass graft (CABG) surgery is a common cardiothoracic procedure. The outcome of this surgery is in part related to the incidence of myocardial ischemic events during the procedure. Reducing these episodes and providing improved myocardial tolerance to them should improve the outlook for these patients.

\section{Aims}

This study investigates the safety and utility of the naturally occurring purine analogue adenosine when used as an additive to a cardioplegia solution in patients undergoing elective CABG surgery.

\section{Methods}


A double blind multicenter study was constructed. Patients undergoing elective CABG were divided into three groups to receive varying intra-operative cardioplegia solutions: standard cold cardioplegia solution (control); cold cardioplegia solution plus $500 \mu \mathrm{M}$ adenosine, and cold cardioplegia solution plus $2 \mathrm{mM}$ adenosine. Those receiving adenosine additives also had an infusion of adenosine $10 \mathrm{~min}$ before and $15 \mathrm{~min}$ after aortic cross-clamping. (It is not clear, however, how double blinding was maintained in this scenario.) The groups were otherwise matched for age, cardiac event history and hematological parameters. The primary outcomes of total dopamine use in the first week, total inotrope use and high dopamine administration were measured. Secondary end points included the incidence of death, myocardial infarction and the need for intra-aortic balloon pumping (IABP).

\section{Results}

A total of 253 patients were enrolled, 84 into the control and low dose adenosine groups and 85 in the high dose group. The results were analysed on an intention to treat basis. The use of dopamine and, in fact, any inotrope was similar in the first 7 days between the groups. There was, however, a nonsignificant trend to use less high dose dopamine and adrenaline in the $2 \mathrm{mM}$ adenosine group compared to placebo, paralleled by a similar trend in reduced mortality.Significantly fewer myocardial infarcts occurred in the higher adenosine group compared to placebo. Additionally, a composite analysis of the use of IABP, adrenaline, high dose dopamine, occurrence of myocardial infarction and death revealed a significant lower incidence in the $2 \mathrm{mM}$ adenosine group versus placebo.

\section{Discussion}

This study provides data to support the possible benefit of adenosine in reducing complications of CABG surgery. It demonstrates the safety of adenosine compared to standard therapy. It additionally provides some suggestion that it may reduce postoperative inotropic requirements.

\section{References}

1. Mentzer RMJr, Birjiniuk V, Khuri S, Lowe JE, Rahko PS, Weisel RD, Wellons HA, Barker ML, Lasley RD, Lasley RD : Adenosine myocardial protection. Preliminary results of a phase II clinical trial. Ann Surg. 1999, 229: 643-650. 